Foro, Nueva época, vol. 19, núm. 1 (2016): 65-76

ISSN:1698-5583

http://dx.doi.org/10.5209/FORO.53387

\title{
EL DERECHO ADMINISTRATIVO Y LA ACTIVIDAD RELACIONAL DE LAS ENTIDADES DE DERECHO PRIVADO DE LA ADMINISTRACIÓN
}

\author{
José Ignacio LóPEZ GonZÁLEZ \\ Catedrático de Derecho Administrativo \\ Facultad de Derecho \\ Universidad Pablo de Olavide (Sevilla) \\ jilopgon@upo.es
}

\begin{abstract}
RESUMEN
Se analizan en este ensayo las cuestiones atinentes al régimen jurídico de las entidades de Derecho privado vinculadas a la Administración a los efectos de determinar sus implicaciones sustantivas y procesales.
\end{abstract}

Palabras clave: Derecho administrativo, entidades de Derecho privado, potestades administrativas, actividad relacional, jurisdicción contencioso-administrativa, procedimiento administrativo.

\section{ABSTRACT}

In this essay we study the issues related to the legal system of the Private Law entities connected with the Administration to the effect of mapping out its core and court implications.

Keywords: Administrative Law, Private Law entities, administrative powers, relational activities, argumentative-administrative jurisdiction, administrative proceedings.

\section{ZUSAMMENFASSUNG}

In diesem Essay werden die Fragen der rechtlichen Regelung der Unternehmen des Privatrechts untersucht, die mit der öffentlichen Verwaltung zusammenarbeiten, um Ihre verfabrensrechtliche und materielle Beteiligung zu definieren.

Schlüsselwörter: Verwaltungsrecht, Gesellschaften des Privatrechts, Befugnisse der Verwaltungen, bezogene Unternehmenstätigkeit, Rechtsprechung der Verwaltungsgerichte, Verwaltungsverfahren. 
SUMARIO: I. LA GRAN NOVEDAD INTRODUCIDA POR LA LEY 39/2015, DEL PROCEDIMIENTO ADMINISTRATIVO COMÚN, Y POR LA LEY 40/2015, DE RÉGIMEN JURÍDICO DEL SECTOR PÚBLICO. EL EJERCICIO DE POTESTADES ADMINISTRATIVAS POR LAS ENTIDADES DE DERECHO PRIVADO DE LA ADMINISTRACIÓN.-II. LA INSATISFACTORIA LIMITACIÓN NEGATIVA POR EL LEGISLADOR DE LA ACTIVIDAD RELACIONAL DE LAS ENTIDADES DE DERECHO PRIVADO DE LA ADMINISTRACIÓN.-III. LA EXPANSIÓN DEL SISTEMA DE RESPONSABILIDAD DE LAS ADMINISTRACIONES PÚBLICAS A LAS ENTIDADES DE DERECHO PRIVADO DE LA ADMINISTRACIÓN.-IV. LA CLÁUSULA DE RETORNO AL DERECHO ADMINISTRATIVO PROTAGONIZADA POR LOS ARTS. 2.2.b) Y 35 DE LA LEY 40/2015, Y LA NECESARIA MODIFICACIÓN DE LA LEY JURISDICCIONAL.

I. LA GRAN NOVEDAD INTRODUCIDA POR LA LEY 39/2015, DEL PROCEDIMIENTO ADMINISTRATIVO COMÚN, Y POR LA LEY 40/2015, DE RÉGIMEN JURÍDICO DEL SECTOR PÚBLICO. EL EJERCICIO DE POTESTADES ADMINISTRATIVAS POR LAS ENTIDADES DE DERECHO PRIVADO DE LA ADMINISTRACIÓN

Más allá de las múltiples novedades de carácter general y particular que protagonizarán tanto la Ley 39/2015 como la Ley 40/2015 a partir de su entrada en vigor el próximo 2 de octubre de 2016, deseo llamar la atención acerca de una novedad legislativa importante, en mi opinión, para el Derecho administrativo de nuestros días y para la salvaguarda de las garantías jurídicas de los particulares, como es el reconocimiento por ambas leyes, en sendos arts. 2.2, letra $b$ ), del ejercicio de potestades administrativas por las entidades de Derecho privado vinculadas o dependientes de la Administración Pública. Los citados preceptos — al enumerar los organismos y entidades que integran el denominado sector público institucional— se refieren a:

«Las entidades de Derecho privado vinculadas o dependientes de las Administraciones Públicas que quedarán sujetas a lo dispuesto en las normas de esta Ley que específicamente se refieran a las mismas y, en todo caso, cuando ejerzan potestades administrativas».

Por su parte, la Ley 40/2015, de Régimen Jurídico del Sector Público, incorpora además la sujeción de estas entidades de Derecho privado «a los principios previstos en el art. 3», que tienen que ver con los principios de 
actuación y de carácter relacional propios de las Administraciones Públicas que habrán de observarse por imperativo legal cualquiera que sea la forma de gestión directa de los servicios públicos, entre cuyas modalidades, como es sabido, figura la prestación mediante entidades de Derecho privado (sociedades mercantiles y fundaciones del sector público) vinculadas o dependientes de la Administración. Igualmente, el art. 81, de carácter básico, de la citada Ley 40/2015, complementando los arts. 2.2.b) y 3 , regula los principios generales de actuación de las entidades que integran el sector público institucional.

La novedad introducida en el actual Derecho administrativo a partir de esta auténtica regla de oro que establecen los citados artículos de estas leyes significa el reconocimiento formal y expreso, con todas sus consecuencias, del ejercicio de potestades administrativas por entidades de Derecho privado del sector público con la finalidad de reconducir al Derecho administrativo el control del ejercicio de competencias administrativas por parte de éstas.

Se abandona así de forma definitiva en nuestro Derecho administrativo el sistema de meros límites o prohibiciones legales que durante décadas ha regido - como criterio único- el comportamiento de las Administraciones Públicas a la hora de crear entidades de Derecho privado y disciplinar sus relaciones con terceros: el criterio de «no poder disponer de facultades que impliquen ejercicio de autoridad pública» o «potestades públicas». Este criterio legal de carácter prohibitivo — pretendidamente garantista - ha motivado indirectamente la inaplicación del Derecho administrativo a verdaderas funciones y competencias administrativas gestionadas por sociedades mercantiles y fundaciones del sector público.

Esta ausencia del Derecho administrativo para garantizar el ejercicio por sujetos privados de competencias administrativas no se ha dado en otros ámbitos de esta disciplina, como, por ejemplo, en el régimen jurídico de las actividades de los concesionarios de servicios públicos o en el régimen jurídico de particulares y entidades privadas colaboradoras de la Administración en múltiples sectores como el de seguridad y calidad industrial, medioambiental, eficiencia energética, etc., dado que el legislador sectorial ha venido dotando, en estos casos, de un estatuto de Derecho público al régimen jurídico relacional de estos particulares y entidades en el ejercicio de funciones y competencias administrativas conferidas a los mismos.

Paradójicamente, tal realidad no ha estado presente en el régimen jurídico relacional de las entidades de Derecho privado de la Administración, salvedad hecha de la normativa interna de dichas entidades, de carácter 
presupuestario, contable, de control financiero y, más recientemente (a partir de la Ley 62/2003 de reforma del Real Decreto Legislativo 2/2000), en disposiciones de contratación (normas de adjudicación, en unos casos, o meras normas de publicidad y concurrencia, en otros).

Frente a la llamada de atención que en el año 1962 hiciera mi maestro, el profesor Clavero Arévalo, acerca del fenómeno ya detectable entonces de la «huida de la aplicación del Derecho administrativo», con referencia al progresivo crecimiento del sector público empresarial de Derecho privado creado para la gestión de servicios públicos de titularidad estatal y local, y con posterioridad generosamente acrecentado por las Comunidades Autónomas, hemos de felicitarnos hoy porque el legislador con las Leyes 39/2015 y 40/2015 (cincuenta y tres años después) decide resueltamente que las entidades de Derecho privado de la Administración quedarán sujetas a lo dispuesto en las normas de estas leyes que específicamente se refieran a las mismas y, en todo caso, cuando ejerzan potestades administrativas.

Podemos decir que el legislador, utilizando una expresión similar a la utilizada en el art. 2.2 de la Ley 30/1992 para las entidades de Derecho público de la Administración, procede a positivizar lo que podríamos denominar la vuelta al Derecho administrativo, tras el reconocimiento formal de que muchas de estas entidades de Derecho privado ejercen funciones y competencias administrativas (gestión de subvenciones públicas, por ejemplo), y que el régimen jurídico aplicable a dichas actuaciones - que no difieren mucho del ejercicio de potestades administrativas por otros sujetos privados, como son los concesionarios de servicios públicos y las entidades colaboradoras de la Administración - no puede ser otro que el Derecho administrativo, debiendo corresponder su control a los órganos de la jurisdicción contencioso-administrativa.

\section{LA INSATISFACTORIA LIMITACIÓN NEGATIVA POR EL LEGISLADOR DE LA ACTIVIDAD RELACIONAL DE LAS ENTIDADES DE DERECHO PRIVADO DE LA ADMINISTRACIÓN}

Si analizamos detenidamente la legislación estatal y autonómica relativa a los límites legales al ejercicio por las Administraciones Públicas de su potestad de autoorganización referida a la creación de entidades de Derecho privado, observamos lo siguiente: 
En lo que se refiere a la legislación del Estado, han sido leyes de carácter organizativo las que han llevado a cabo diversas regulaciones acerca de los límites al ejercicio de la potestad organizativa de la Administración a efectos de la creación de entidades de Derecho privado.

En el año 1985, la Ley 7/1985, de Bases de Régimen Local, en su art. 85.3 (el originario) establecía una prohibición equívoca al afirmar que: «En ningún caso podrán prestarse por gestión indirecta los servicios públicos que impliquen ejercicio de autoridad» (sabido es que las entidades de Derecho privado de la Administración son formas personificadas de gestión directa de los servicios públicos). Con ligera variación del texto y con el mismo error de fondo, el Real Decreto Legislativo 781/1986, por el que se aprobó el texto refundido de las disposiciones legales vigentes en materia de régimen local, afirmaba en su art. 95.1 que: «Los servicios que impliquen ejercicio de autoridad sólo podrán ser ejercidos por gestión directa». Habrá que esperar a la reforma de la Ley 7/1985 llevada a cabo por la Ley 57/2003, de Medidas de Modernización del Gobierno Local, para llegar a la redacción actual del art. 85.3, que con mayor precisión establece que: «En ningún caso podrán prestarse por gestión indirecta ni mediante sociedad mercantil de capital social exclusivamente local los servicios públicos que impliquen ejercicio de autoridad». No se dice nada de las fundaciones, dado que su especial desarrollo en el sector público lo han protagonizado la Administración General del Estado y las Administraciones Autonómicas.

En el año 1997, con referencia a las sociedades mercantiles estatales, la disposición adicional duodécima de la Ley 6/1997, de Organización y Funcionamiento de la Administración General del Estado, establece que: «En ningún caso podrán disponer de facultades que impliquen el ejercicio de autoridad pública».

En el año 2002, la Ley 50/2002, de Fundaciones del Estado, establecía en su art. 46.1, con referencia a las fundaciones del sector público estatal, que: «No podrán ejercer potestades públicas». Este precepto, por cierto, quedará derogado con la entrada en vigor de la Ley 40/2015, de Régimen Jurídico del Sector Público, si bien el nuevo art. 128.2 de esta Ley destinado a las fundaciones del sector público estatal reitera la misma expresión que la de la Ley del 2002.

En el año 2007, la Ley 7/2007, por la que se aprobó el Estatuto Básico del Empleado Público (hoy regulado por el Real Decreto Legislativo 5/2015), determina expresamente en su art. 9.2 que: «En todo caso, el ejercicio de las funciones que impliquen la participación directa o indi- 
recta en el ejercicio de las potestades públicas o en la salvaguardia de los intereses generales del Estado y de las Administraciones Públicas corresponden exclusivamente a los funcionarios públicos en los términos que en la ley de desarrollo de cada Administración Pública se establezca».

Este precepto ha operado siempre para la Administración Pública —no obstante su indeterminación- como un referente limitador de competencias atribuibles a las entidades de Derecho privado, dada la ausencia en las mismas de este personal.

En la legislación de Andalucía (al igual que en otras Comunidades Autónomas) encontramos, asimismo, previsiones relativas a los límites legales que el Derecho propio de Andalucía, en concreto la Ley 9/2007, de la Administración de la Junta de Andalucía, establece respecto de las denominadas «entidades instrumentales privadas del sector público andaluz», constituido por las sociedades mercantiles y las fundaciones creadas por la Administración autonómica.

La Ley 9/2007, de la Administración de la Junta de Andalucía, clasifica las entidades instrumentales de la Administración autonómica (art. 52) en agencias y entidades de Derecho privado. Por su parte, el art. 1.2 afirma de modo indiferenciado que las entidades instrumentales de la Administración de la Junta de Andalucía (agencias y entidades de Derecho privado, según ha quedado dicho) «sujetarán su actividad a esta ley en todo caso cuando actúen en el ejercicio de potestades administrativas». Pero más adelante, al regular el régimen jurídico de las sociedades mercantiles y fundaciones del sector público andaluz, viene a establecer (art. 52.3) lo siguiente: «Las sociedades mercantiles y las fundaciones del sector público andaluz [...] en ningún caso podrán disponer de facultades que impliquen ejercicio de autoridad». Con referencia a las sociedades mercantiles del sector público andaluz, el art. 75.2 afirma que «en ningún caso podrán ejercer potestades administrativas». En cuanto al régimen específico de las fundaciones del sector público andaluz, el art. 78 reenvía a lo establecido anteriormente en la Ley 10/2005, de Fundaciones de la Comunidad Autónoma de Andalucía, en la que, al igual que en la Ley estatal de Fundaciones, se reafirma que «las fundaciones del sector público de la Comunidad Autónoma de Andalucía no podrán ejercer potestades públicas».

En definitiva, y como hemos podido comprobar, la legislación utiliza con escaso rigor técnico expresiones diversas para delimitar el ámbito funcional que le está prohibido a la Administración Pública a la hora de crear entidades de Derecho privado del sector público, tales como «no poder ejercer potestades públicas», «no poder ejercer potestades adminis- 
trativas» o «no disponer de facultades que impliquen ejercicio de autoridad pública». En consecuencia, y a la vista del nuevo art. 2.2.b) de la Ley 39/2015 y de la Ley 40/2015, que reconoce a estas entidades el ejercicio de potestades administrativas, resulta obligado analizar los conceptos $\mathrm{y}$, en su caso, la distinta naturaleza jurídica de los mismos.

La delimitación conceptual se hace más urgente, dado que la Ley 40/2015, de Régimen Jurídico del Sector Público, no ha sido capaz de sustraerse a la incertidumbre que tradicionalmente venimos padeciendo; así, la Ley 40/2015, en relación con el régimen de las fundaciones del sector público estatal, declara expresamente en su art. 128.2 que «las fundaciones no podrán ejercer potestades públicas». Más adelante, y en relación con las sociedades mercantiles estatales, la citada Ley 40/2015 en su art. 113 determina que: «En ningún caso podrán disponer de facultades que impliquen el ejercicio de autoridad pública, sin perjuicio de que excepcionalmente la ley pueda atribuirle el ejercicio de potestades administrativas».

Siguiendo al profesor Gamero Casado en su monografía Desafíos del Derecho administrativo ante un mundo en disrupción (galardonada el pasado año con el premio «Angel Olavarría de Estudios Jurídicos» de la Real Academia Sevillana de Legislación y Jurisprudencia), cabe afirmar que el concepto de potestad administrativa se corresponde con el conjunto de atribuciones cuya titularidad el ordenamiento jurídico atribuye a la Administración para satisfacer el interés general y cuyo ejercicio se somete en todo caso al Derecho administrativo y al control por los Juzgados y Tribunales de lo Contencioso-Administrativo.

$\mathrm{Al}$ igual que no todas las potestades administrativas se reconocen o atribuyen a todas las Administraciones Públicas (por ejemplo, la potestad reglamentaria, la potestad expropiatoria, la potestad sancionadora, etc.), no todas las potestades administrativas implican, asimismo, ejercicio de imperium, es decir, comportan un poder coercitivo (como, por ejemplo, las potestades de autotutela, imposición de sanciones, etc.). No es exacto que los conceptos de prerrogativa, privilegio y poderes exorbitantes sean comunes a todas las potestades administrativas; por el contrario, estas características son propias tan sólo de determinadas potestades públicas asignadas a la Administración, que por implicar ejercicio de imperium y autoridad pública su ejercicio queda reservado por la ley a los funcionarios públicos.

En consecuencia, los conceptos de «potestad pública» (con referencia a la Administración) y «facultades o potestades que implican ejercicio de autoridad pública» representan funciones de autoridad, de imperium y de coacción legítima en poder de la Administración Pública —en los térmi- 
nos que le venga atribuida la titularidad por la Constitución y/o las leyes-, cuyo ejercicio queda reservado a los funcionarios públicos. De ahí la obligada ausencia de este tipo de potestades administrativas entre los fines y atribuciones de las entidades de Derecho privado del sector público.

Precisamente lo que se ha echado de menos en nuestro Derecho administrativo - desde hace décadas - ha sido el reconocimiento expreso e indubitado de esta realidad: el ejercicio de potestades administrativas por parte de entidades privadas del sector público. Esta laguna u omisión del legislador ha posibilitado la existencia de ámbitos de inmunidad en el ejercicio de competencias administrativas en régimen de gestión directa bajo formas de personificación de Derecho privado, impidiendo con ello la aplicación del Derecho administrativo como ordenamiento común del ejercicio de las potestades administrativas, cualquiera que sea el sujeto que — de conformidad con la ley_ las tenga atribuidas.

Es posible recordar la Sentencia del Tribunal Supremo de 24 de noviembre de 2009 en la que, siendo parte demandada la Junta de Andalucía, se vino a invalidar (al cabo de diez años) el Decreto 117/1998, del Consejo de Gobierno, por el que se modificaban los estatutos de EGMASA (Empresa de Gestión Medioambiental, Sociedad Anónima) para ampliar el objeto social de esta empresa a la «gestión de los servicios públicos en materia medioambiental que le puedan ser atribuidos por la Administración competente». El Tribunal Supremo (lo que no hizo en su día el Tribunal Superior de Justicia de Andalucía) declaró la nulidad del decreto frente a las pretensiones de la Administración de tratarse de una disposición de mera autoorganización. En concreto, en el Fundamento de Derecho 9. ${ }^{\circ}$ de la Sentencia se afirma categóricamente que «la mayor eficacia y agilidad en la gestión de los servicios públicos a través de formas jurídico-privadas no puede suponer un quebranto en las garantías de los derechos de los ciudadanos. El riesgo de merma de esos derechos se plasma con la cada vez mayor asunción por parte de entes públicos instrumentales, bajo formas privadas, de actuaciones y servicios públicos sin el pleno control de las normas administrativas y de la jurisdicción contencioso-administrativa».

En este sentido, la cláusula de retorno al Derecho administrativo que protagoniza el art. 2.2, letra b), de estas leyes (Ley 39/2015 y Ley 40/2015) significa una reducción más de inmunidades del poder público administrativo y la reafirmación del Derecho administrativo como el Derecho común de las Administraciones Públicas, y por ello de las potestades administrativas cuya titularidad les viene atribuida por la ley, ya las ejerzan directa- 
mente (por la propia Administración territorial o a través de entidades de Derecho público o entidades de Derecho privado creadas por ella) o de forma indirecta.

Se trata, pues, de una verdadera regla de oro aportada por el legislador, en una de esas pinceladas brillantes con las que muy de cuando en cuando nos sorprende. Para mí comparable, por ejemplo, con el tratamiento dado a los «actos políticos del gobierno» por la Ley de la Jurisdicción Contencioso-Administrativa de 1998, que de constituir el concepto un límite al control jurisdiccional en el marco de la vieja Ley de la Jurisdicción de 1956, se contempló por el legislador en el art. 2, letra a), de la Ley 29/1998 vigente en términos de regulación positiva, dejando claro — de una vez por todas- que cualquiera que fuese la naturaleza de los actos del gobierno, «la protección de los derechos fundamentales, los elementos reglados y la determinación de las indemnizaciones que fueran procedentes» son del conocimiento pleno del orden jurisdiccional contencioso-administrativo. Con ello el concepto de acto político del gobierno dejó de suscitar polémi$\mathrm{ca}$, poniéndose punto final a un ámbito de inmunidad al control jurisdiccional de importantes actuaciones del poder ejecutivo.

\section{LA EXPANSIÓN DEL SISTEMA DE RESPONSABILIDAD DE LAS ADMINISTRACIONES PÚBLICAS A LAS ENTIDADES DE DERECHO PRIVADO DE LA ADMINISTRACIÓN}

En esta vuelta al Derecho administrativo que postula el art. 2 de las nuevas leyes, tratándose de actuaciones del sector público de Derecho privado (sociedades mercantiles y fundaciones) existe una segunda pieza nuclear importantísima protagonizada por el nuevo art. 35 de la Ley 40/2015, que bajo el mismo título de «Responsabilidad de Derecho privado» (aunque mejor debiera decir «Responsabilidad por actuaciones de Derecho privado») viene a sustituir al actual art. 144 de la Ley 30/1992, si bien su contenido difiere: en el actual se pretende poner de manifiesto que cualquiera que sea la naturaleza de la actividad (pública o privada) o el tipo de relación de que derive el daño causado por la Administración, el régimen jurídico aplicable será el de los arts. 139 y ss. de la citada Ley; es decir, el sistema de responsabilidad por daños de la Administración no varía, con independencia de la naturaleza de la actividad o el tipo de relación en que la Administración ocasione el daño. Sin embargo, el interés del 
nuevo precepto consiste en que el legislador del art. 35 va más allá, estableciendo lo siguiente:

«Cuando las Administraciones Públicas actúen, directamente o a través de una entidad de Derecho privado, en relaciones de esta naturaleza, su responsabilidad se exigirá de conformidad con lo previsto en los arts. 32 y siguientes, incluso cuando concurra con sujetos de Derecho privado o la responsabilidad se exija directamente a la entidad de Derecho privado a través de la cual actúe la Administración o a la entidad que cubra su responsabilidad».

La gran novedad del art. 35 de la Ley 40/2015 consiste en extender y aplicar el actual sistema de responsabilidad patrimonial de las Administraciones Públicas diseñado en los arts. 139 y ss. de la vigente Ley 30/1992 o — a partir del 2 de octubre de 2016 - en los arts. 32 y ss. de la Ley 40/2015, de Régimen Jurídico del Sector Público, a los daños causados a terceros por las entidades de Derecho privado del sector público, lo cual no es posible, como se ha dicho, reconocer todavía hoy en el marco del art. 144 de la Ley 30/1992, cuya redacción trae causa de la Ley 4/1999 y se refiere a daños ocasionados en todo caso por una Administración Pública, sin que fuera posible extender este régimen de responsabilidad a las entidades de Derecho privado dependientes o vinculadas a la Administración, que es la gran aportación del nuevo art. 35 de la Ley 40/2015.

\section{LA CLÁUSULA DE RETORNO AL DERECHO ADMINISTRATIVO PROTAGONIZADA POR LOS ARTS. 2.2.b) Y 35 DE LA LEY 40/2015, Y LA NECESARIA MODIFICACIÓN DE LA LEY JURISDICCIONAL}

Tal es el alcance y significación de este importante precepto que, junto al art. 2.2, letra b), de las Leyes 39/2015 y 40/2015, constituye, como he reiterado, una verdadera regla de oro o cláusula de retorno y sometimiento al Derecho administrativo de actividades de las entidades de Derecho privado de las Administraciones Públicas que hasta la fecha - aun desempeñando potestades administrativas - no venían sujetas al Derecho público administrativo. Por ello, el alcance de esta cláusula de retorno resulta determinante para la aplicación a estas entidades de un nuevo régimen 
jurídico de Derecho público integrado por: a) la aplicación de los principios generales de los arts. 3. ${ }^{\circ}$ y 81 de la Ley 40/2015, que deben ser tenidos en cuenta en su actuación y relaciones por las entidades de Derecho privado de la Administración; b) la aplicación de las Leyes 39/2015 y 40/2015 cuando dichas entidades ejerzan potestades administrativas, y, finalmente, c) la aplicación del sistema de responsabilidad patrimonial de las Administraciones Públicas a las entidades de Derecho privado del sector público. Todo ello representa mayor seguridad jurídica y el restablecimiento del Derecho público administrativo como ordenamiento común de las Administraciones Públicas, titulares de potestades administrativas para la satisfacción del interés general.

Queda por completar ciertamente el nuevo régimen jurídico así diseñado, con los procedimientos para dar plena efectividad a estas determinaciones legales, tanto en vía administrativa como en sede contencioso-administrativa.

Entendemos que la ampliación del ámbito de aplicación del Derecho administrativo a estas entidades de Derecho privado se corresponde, de una parte, con el concepto moderno del sector público enraizado en el Derecho comunitario europeo y, de otra, con el preceptivo régimen de Derecho público aplicable al ejercicio de las potestades administrativas y al sistema de responsabilidad patrimonial de la Administración, indisponible para la Administración y no susceptible de inaplicación mediante el ejercicio de su potestad organizativa; es decir, la creación por la Administración de entidades de Derecho privado no puede frustrar el régimen de Derecho administrativo propio del ejercicio de potestades administrativas, así como la aplicación a todas las actuaciones de la Administración del sistema público de responsabilidad patrimonial, tanto cuando actúe ella o lo haga a través de una entidad de Derecho privado del sector público. De otro modo, el sistema resultante constituiría materialmente una conducta de la Administración en fraude de ley y de la Constitución, con la correspondiente merma de seguridad y garantías jurídicas para los particulares afectados.

Resta ahora por completar el nuevo régimen de Derecho administrativo aplicable a las entidades de Derecho privado creadas por la Administración Pública en lo relativo al ejercicio de potestades administrativas y responsabilidad patrimonial por daños, con la consiguiente adaptación de la Ley de la Jurisdicción Contencioso-Administrativa a esta nueva realidad.

Las nuevas determinaciones de las Leyes 39/2015 y 40/2015 en esta materia, así como las determinaciones similares que encontramos en otras importantes leyes administrativas estatales (por ejemplo, la Ley 19/2013, de 9 de diciembre, sobre transparencia, acceso a la información pública 
y buen gobierno, y las correspondientes leyes autonómicas de este grupo normativo), vienen a residenciar ante la jurisdicción contencioso-administrativa la interposición de recursos frente a actuaciones de sociedades mercantiles públicas y fundaciones públicas que produzcan daños a terceros o lesionen el derecho de acceso a la información pública que obre en su poder [art. 2, letras g) y b), de la Ley 19/2013], sin que hasta la fecha se haya procedido a adaptar la Ley jurisdiccional 29/1998 a la ampliación del ámbito objetivo y subjetivo de esta jurisdicción. Aspectos relativos al ámbito objetivo (art. 1), parte demandada (art. 21) y objeto del recurso contencioso (art. 25) precisan integrar la nueva realidad que nos ofrecen - entre otras- las Leyes 39/2015 y 40/2015. Es preciso sustantivar el ejercicio de potestades administrativas de cara a la necesaria reforma de la Ley de la Jurisdicción Contencioso-Administrativa. 